\title{
A relação entre saberes e práticas espirituais e o processo saúde-doença: revisão integrativa
}

\author{
The relationship between spiritual knowledge \\ and practices in the health-disease process: \\ integrative review
}

\author{
Francisco Jaime Rodrigues de Lima Filho ${ }^{1}$ \\ Nalva Kelly Gomes de Lima² \\ Natália Rodrigues Vieira ${ }^{3}$ (1)
}

${ }^{1}$ Autor para correspondência. Fundação Oswaldo Cruz, Secretaria de Saúde do Município do Paulista (Paulista). Pernambuco, Brasil. jaimefilho-crato@hotmail.com 2Universidade de Pernambuco (Recife), Universidade Estadual da Paraíba (Campina Grande). Pernambuco, Paraíba, Brasil. nalvakellygomes@gmail.com 3Universidade Regional do Cariri (Crato). Ceará, Brasil. vieirarodriguesnaty@gmail.com

RESUMO | OBJETIVO: identificar como os saberes e as práticas espirituais se relacionam com o processo saúdedoença dos sujeitos. MÉTODOS E MATERIAIS: trata-se de uma revisão integrativa da literatura, desenvolvida nas bases de dados SCIELO, LILACS, BDENF, CINAHL e MEDLINE, com os descritores "espiritualidade", "Cura pela fé" e "Processo saúdedoença", associados com o operador booleano "and". Como critérios de inclusão adotaram-se: pesquisas originais, nos idiomas inglês, português e espanhol, entre os anos de 2008 e 2018, disponíveis na íntegra de forma gratuita. RESULTADOS: identificaram-se 16 trabalhos científicos nas bases de dados. A análise dos achados originou três categorias temáticas: A influência da religiosidade em situações específicas de adoecimento; Os profissionais de saúde e a espiritualidade; Saberes e práticas espirituais e a sua relação com o processo saúde-doença. CONSIDERAçõES FINAIS: observou-se que a espiritualidade é visualizada como uma importante forma de enfrentamento pessoal para as pessoas que passam por processos de adoecimento crônicos, além de servir como meio para o apoio social desses indivíduos. As principais práticas de cura relatadas na literatura foram os banhos, as rezas e benzimentos e as oferendas. Os profissionais enxergam essa temática como algo necessário no processo de cuidar, muito embora não acreditem terem passado por um processo de formação que levasse essas questões em consideração.

DESCRITORES: Espiritualidade. Cura pela fé. Processo saúdedoença.
ABSTRACT | OBJECTIVE: to identify how spiritual knowledge and practices are related to the health-disease process of the subjects. METHODS AND MATERIALS: this is an integrative review of the literature developed in the databases SCIELO, LILACS, BDENF, CINAHL and MEDLINE. The descriptors were "spirituality", "healing by faith" and "health-disease process". These descriptors were associated with the Boolean operator "and". As inclusion criteria, original researches (in English, Portuguese and Spanish) were adopted between 2008 and 2018. These surveys are available in full for free. RESULTS: 16 scientific studies were identified in the databases. Data analysis originated three thematic categories: the influence of religiosity in specific situations of illness; health professionals and spirituality; spiritual knowledge and practices and its relationship with the health-disease process. FINAL CONSIDERATIONS: it was observed that spirituality is seen as an important form of personal confrontation for people who go through chronic illness processes. In addition, it serves as a means for the social support of these individuals. The main healing practices reported in the literature were baths, prayers, spells and offerings. Professionals see this theme as something necessary in the care process, although they do not believe they have gone through a training process that takes these issues into consideration.

DESCRIPTORS: Spirituality. Healing by faith. Health-disease process. 


\section{Introdução}

A espiritualidade compreende aspectos relacionados ao entendimento do que é a vida e a razão de viver, não estando limitada a nenhuma crença ou prática específica. Difere da religião devido ao fato dessa necessitar de um sistema de doutrinas específicas que são partilhadas por um determinado grupo de pessoas. Por outro lado, a espiritualidade se debruça sobre as questões existenciais acerca da vida, da sua relação com o sagrado ou com o transcendente, não havendo a obrigatoriedade de envolvimento com comunidades ou cultos religiosos 1, .

Estudo $^{3}$ que aborda o panorama das pesquisas em ciência, saúde e espiritualidade e a interrelação entre estes dois temas tem crescido nas últimas décadas no Brasil e no mundo. Segundo os autores muitos desses estudos preocupam-se em evidenciar a influência que a dimensão espiritual tem sobre aspectos da qualidade de vida das pessoas e com o processo saúde-doença das mesmas. O estudo aponta ainda que o Brasil se destaca como um dos grandes produtores de conhecimento acadêmico relacionado à temática, tendo em vista que no ano de 2015 ocupava o quinto lugar dentre os países que mais publicavam sobre o tema na base Scopus. Vale destacar ainda, que a preocupação com a formação dos profissionais de saúde sensibilizados com essas questões tem crescido, evidenciado pelo aumento de disciplinas que debatem tais questões nas grades curriculares de cursos de graduação 3 .

Evidencia-se na literatura que a espiritualidade coloca-se como uma estratégia capaz de potencializar comportamentos saudáveis, assim como auxiliar na recuperação da saúde, principalmente quando relacionada às doenças crônicas e a terminalidade da vida. Salienta-se, contudo, que também existem estudos que indicam fatores negativos associados à espiritualidade no campo da saúde ${ }^{4,5}$.

Estudos desenvolvidos com pacientes portadores de doenças crônicas evidenciaram que a religiosidade e a espiritualidade estiverem relacionadas a uma meIhor aceitação da condição de saúde, maior colaboração com os profissionais de saúde com consequente melhoria na adesão ao tratamento, menores índices de ansiedade, desesperança, depressão e suicídio, além de aumentar a satisfação com a vida $a^{6-7}$.

Salienta-se que a compreensão de aspectos relacionados à espiritualidade e ou religiosidade está intimamente ligada ao entendimento do cuidado integral dos indivíduos, que busca visualizá-los de acordo com várias dimensões, não apenas ligada a questões biológicas, mas também sob paradigmas sociais, mentais e espirituais ${ }^{8}$. Tal entendimento permite superar o modelo médico hegemônico centrado na doença, ao passo que os profissionais da saúde orientam esforços para garantir bem-estar e qualidade de vida para os usuários dos serviços de saúde, orientados por uma lógica assistencial que também considera aquilo que não é palpável e visível?

As práticas espirituais podem configurar-se como um tipo de medicina tradicional, definida pela Organização Mundial da Saúde (OMS) como aquela proveniente de um conjunto de teorias, crenças e experiências indígenas, orientadas para o cuidado da saúde de populações ${ }^{10}$.

Nesse sentido, o presente artigo tem como objetivo identificar como os saberes e as práticas espirituais se relacionam com o processo saúde-doença dos sujeitos.

\section{Métodos e materiais}

Trata-se de uma revisão integrativa da literatura realizada no mês de abril de 2018. A pesquisa foi estruturada de acordo com as seguintes etapas: identificação da questão norteadora do estudo, definição das bases de dados científicos a serem utilizadas, definição dos descritores em ciências da saúde e operadores booleanos, definição de critérios de inclusão e exclusão, busca nas bases de dados, leitura crítica dos trabalhos científicos, discussão e apresentação do relatório final. Para orientar a execução do presente estudo, utilizou-se a seguinte questão norteadora: Quais as relações existentes entre saberes e práticas espirituais e o processo saúde-doença?

Para realização das buscar utilizaram-se as bases de dados da Literatura Latino-Americana em ciências da saúde - LILACS, Base de dados da Enfermagem - BDENF, Medical Literature Analysis and Retrieval System Online - MEDLINE (via portal CAPES), Cumulative Index of Nursing and Allied Health CINAHL (via portal CAPES) e a biblioteca virtual em saúde Scientific Electronic Library Online - SciELO.

Utilizou-se descritores de assunto baseados nos componentes da questão norteadora que estavam 
listados como Descritores em Ciências da Saúde (Decs) e Medical Subject Headings (MeSH), sendo eles "espiritualidade", "cura pela fé" e "processo saúde-doença", associados nas bases de dados com o operador booleano "and". Nesse sentido, as pesquisas tiveram as seguintes chaves de busca: "espiritualidade and processo saúde-doença" e "espiritualidade and cura pela fé".

Como critérios de inclusão consideraram-se: artigos publicados em periódicos científicos, dissertações e teses publicadas em repositórios acadêmicos nos idiomas português, inglês e espanhol, entre os anos de 2008 e 2018. Estar disponível na íntegra e de forma gratuita. Consideraram-se apenas trabalhos originais, excluindo-se artigos de revisão, relatos de experiência, relatos de casos clínicos, editoriais e artigos de reflexão. Foram excluídos ainda os estudos repetidos nas bases de dados e os que não estavam diretamente ligados a temática central da revisão integrativa.

Para verificação da viabilidade dos estudos quanto a sua inclusão na revisão adotou-se a estratégia de leitura sistemática por título, resumo e por fim o trabalho na íntegra. No intuito de diminuir vieses na realização do presente estudo, as buscas dos trabalhos científicos foram realizadas por dois revisores, ao passo que eram identificadas discordâncias quanto à inclusão ou exclusão de determinados trabalhos os mesmos discutiam a situação e chegavam a um consenso.
Para a realização da coleta de dados dos artigos que foram incluídos no estudo, utilizou-se o instrumento elaborado por Ursi $(2005)^{11}$. O instrumento que foi submetido à validação aparente e de conteúdo, contempla aspectos relacionados à: identificação do artigo, instituição que o estudo é proveniente, tipo de revista científica, características metodológicas, avaliação do rigor metodológico, as intervenções realizadas e resultados encontrados.

Os artigos incluídos foram analisados de maneira descritiva, no intuito de permitir verificar o atual estado da arte da temática e identificar as necessidades de investigações futuras.

As buscas nas bases de dados resgataram 28 estudos, dos quais 16 foram incluídos na amostra da presente revisão após a leitura de títulos, resumos e trabalhos na íntegra, observando-se os fatores de inclusão e exclusão. Doze artigos foram excluídos por estarem repetidos nas bases de dados, não estarem disponíveis na íntegra, não serem trabalhos originais (revisões da literatura), não estarem dentro do recorte temporal estabelecido (2008 a 2018) ou não responderem o objetivo do presente estudo. Salienta-se que na base de dados MEDLINE não foram encontrados resultados. Na figura a seguir, observam-se as fases que compreenderam a seleção de pesquisas nas bases de dados.

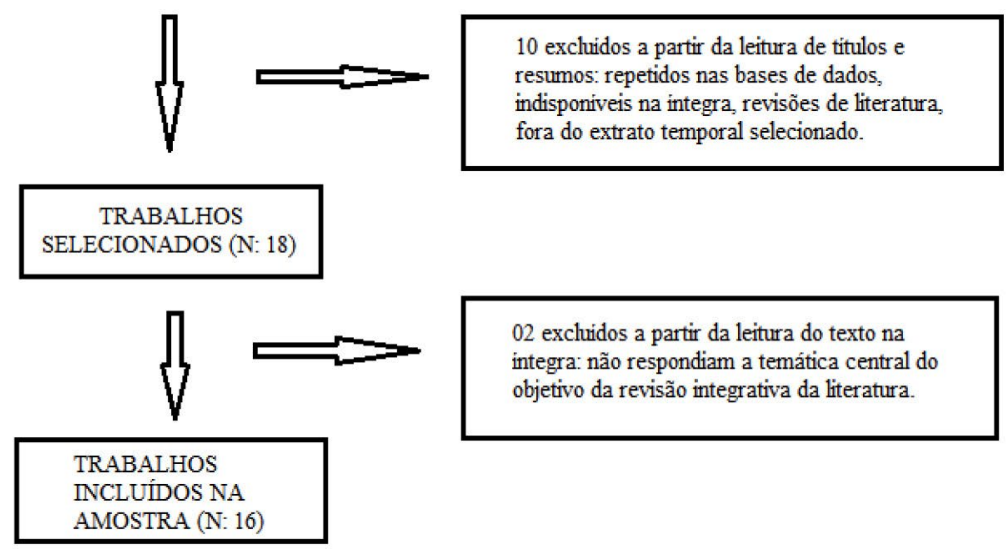




\section{Resultados}

No que diz respeito às características dos estudos incluídos, verifica-se que a maioria estavam indexados na SCIELO, um total de nove estudos. Apenas dois estudos foram desenvolvidos fora do Brasil, no caso, em Portugal, ambos na cidade de Porto. No contexto nacional, os estados com mais estudos foram São Paulo e Rio de Janeiro, ambos com três estudos. Com relação ao tipo de estudo, apenas dois possuíam abordagem quantitativa. O método para a coleta de dados predominante foi a entrevista semiestruturada, sendo a análise de conteúdo o método de análise mais utilizado. Todos os estudos foram publicados na língua portuguesa, sete deles também foram publicados na língua inglesa. A seguir, verifica-se o quadro com informações detalhadas acerca das pesquisas incluídas.

Quadro 1. Descrição dos trabalhos selecionados segundo autoria, ano de publicação, título, objetivo, tipo de estudo e método (continua)

\begin{tabular}{|c|c|c|c|}
\hline $\begin{array}{c}\text { Autoria, ano de } \\
\text { publicação e Base } \\
\text { de dados. }\end{array}$ & Título & Objetivo & $\begin{array}{c}\text { Tipo de } \\
\text { estudo/Método }\end{array}$ \\
\hline $\begin{array}{l}\text { Fernandes (2015) } \\
\text { LILACS }\end{array}$ & $\begin{array}{l}\text { Medicina centrada na } \\
\text { pessoa: o componente } \\
\text { espiritual na abordagem } \\
\text { pelo médico de família e } \\
\text { comunidade } \\
\text { [Dissertação] }\end{array}$ & $\begin{array}{l}\text { Explorar como as questões } \\
\text { espirituais influenciam na } \\
\text { prática clínica de Médicos de } \\
\text { Família e Comunidade. }\end{array}$ & $\begin{array}{l}\text { Qualitativo/Entrevista } \\
\text { semiestruturada e } \\
\text { análise de conteúdo }\end{array}$ \\
\hline $\begin{array}{l}\text { Mello (2013) } \\
\text { LILACS }\end{array}$ & $\begin{array}{l}\text { Práticas terapêuticas } \\
\text { populares e religiosidade } \\
\text { afro-brasileira em } \\
\text { terreiros no Rio de } \\
\text { Janeiro: um diálogo } \\
\text { possível entre saúde e } \\
\text { antropologia. [Tese] }\end{array}$ & $\begin{array}{l}\text { Refletir sobre as maneiras } \\
\text { pelas quais as medicinas } \\
\text { tradicionais podem dialogar } \\
\text { com a biomedicina. }\end{array}$ & $\begin{array}{l}\text { Exploratória qualitativa } \\
\text { de caráter } \\
\text { etnográfico/Entrevistas } \\
\text { abertas, conversas } \\
\text { informais, registro } \\
\text { fotográfico. }\end{array}$ \\
\hline $\begin{array}{l}\text { Portugal (2016) } \\
\text { LILACS }\end{array}$ & $\begin{array}{l}\text { Entre o consultório e o } \\
\text { terreiro: mediações, } \\
\text { ruídos silenciamentos } \\
\text { nos itinerários } \\
\text { terapêuticos de adeptos } \\
\text { do candomblé }\end{array}$ & $\begin{array}{l}\text { Discutir os aspectos } \\
\text { infocomunicacionais } \\
\text { concernentes à relação que } \\
\text { adeptos do candomblé } \\
\text { estabelecem com serviços de } \\
\text { saúde. }\end{array}$ & $\begin{array}{l}\text { Qualitativo/Entrevista } \\
\text { semiestruturada e } \\
\text { análise de conteúdo }\end{array}$ \\
\hline $\begin{array}{l}\text { Soares, Morgan, } \\
\text { Santos, Matozinhos, } \\
\text { Penna (2014) } \\
\text { LILACS }\end{array}$ & $\begin{array}{l}\text { Crenças e práticas de } \\
\text { saúde no cotidiano de } \\
\text { usuários da rede básica } \\
\text { de saúde. }\end{array}$ & $\begin{array}{l}\text { Compreender as influências } \\
\text { culturais sobre os significados e } \\
\text { as práticas de saúde-doença } \\
\text { para usuários da rede básica } \\
\text { de saúde e as suas relações } \\
\text { com os serviços. }\end{array}$ & $\begin{array}{l}\text { Estudo de caso de } \\
\text { abordagem qualitativa } \\
\text { fundamentado na } \\
\text { Sociologia } \\
\text { Compreensiva } \\
\text { do Cotidiano/Entrevista } \\
\text { semiestruturada e } \\
\text { análise de conteúdo }\end{array}$ \\
\hline $\begin{array}{l}\text { Reginato, Benedetto, } \\
\text { Gallian (2016) } \\
\text { SCIELO }\end{array}$ & $\begin{array}{l}\text { Espiritualidade e saúde: } \\
\text { uma experiência na } \\
\text { graduação em medicina } \\
\text { e enfermagem. }\end{array}$ & $\begin{array}{l}\text { Apresentar o perfil dos } \\
\text { estudantes que escolheram } \\
\text { a disciplina eletiva } \\
\text { Espiritualidade e Medicina. }\end{array}$ & $\begin{array}{l}\text { Qualitativo/Questionári } \\
\text { os e Dissertações }\end{array}$ \\
\hline $\begin{array}{l}\text { Pinto, Ribeiro (2010) } \\
\text { SCIELO }\end{array}$ & $\begin{array}{l}\text { Avaliação da } \\
\text { espiritualidade dos } \\
\text { sobreviventes de cancro: } \\
\text { implicações na qualidade } \\
\text { de vida. }\end{array}$ & $\begin{array}{l}\text { Analisar as diferenças da } \\
\text { espiritualidade de acordo com } \\
\text { as variáveis sócio-demográficas } \\
\text { e clínicas num grupo de } \\
\text { sobreviventes de cancro. }\end{array}$ & $\begin{array}{l}\text { Quantitativo/ Aplicação } \\
\text { de escalas para avaliar } \\
\text { espiritualidade e } \\
\text { qualidade de vida. }\end{array}$ \\
\hline $\begin{array}{l}\text { Rocha, Sá, Braga, } \\
\text { Ferreira Filha, Dias } \\
\text { (2013) } \\
\text { SCIELO }\end{array}$ & $\begin{array}{l}\text { Terapia comunitária } \\
\text { integrativa: situações de } \\
\text { sofrimento emocional e } \\
\text { estratégias de } \\
\text { enfrentamento } \\
\text { apresentadas por } \\
\text { usuários. }\end{array}$ & $\begin{array}{l}\text { Identificar os principais } \\
\text { problemas e as formas de } \\
\text { enfrentamento de pessoas que } \\
\text { frequentam Terapia } \\
\text { Comunitária. }\end{array}$ & $\begin{array}{l}\text { Qualitativo/Análise } \\
\text { documental }\end{array}$ \\
\hline
\end{tabular}

Fonte: Os autores (2020). 
Quadro 1. Descrição dos trabalhos selecionados segundo autoria, ano de publicação, título, objetivo, tipo de estudo e método (conclusão)

\begin{tabular}{|c|c|c|c|}
\hline $\begin{array}{l}\text { Cruz, Daspett, Roza, } \\
\text { Ohara, Horta (2015) } \\
\text { SCIELO }\end{array}$ & $\begin{array}{l}\text { Vivência da família no } \\
\text { processo de transplante } \\
\text { de rim de doador vivo. }\end{array}$ & $\begin{array}{l}\text { Compreender a vivência da } \\
\text { família no processo de } \\
\text { transplante de rim de doador } \\
\text { vivo. }\end{array}$ & $\begin{array}{l}\text { Qualitativo/Entrevista } \\
\text { semiestruturada }\end{array}$ \\
\hline $\begin{array}{l}\text { Ferreira, Favoreto, } \\
\text { Guimarães (2012) } \\
\text { SCIELO }\end{array}$ & $\begin{array}{l}\text { The influence of } \\
\text { religiousness on living } \\
\text { with HIV. }\end{array}$ & $\begin{array}{l}\text { Analisar os relatos de pessoas } \\
\text { que vivem com HIV sobre } \\
\text { religiosidade. }\end{array}$ & $\begin{array}{l}\text { Qualitativa/Entrevista } \\
\text { semiestruturada }\end{array}$ \\
\hline $\begin{array}{l}\text { Borges, Furino, } \\
\text { Barbieri, Souza, } \\
\text { Alvarenga, Dupas } \\
\text { (2016) } \\
\text { SCIELO }\end{array}$ & $\begin{array}{l}\text { A rede e apoio social do } \\
\text { transplantado renal. }\end{array}$ & $\begin{array}{l}\text { Conhecer a rede e apoio social } \\
\text { da pessoa que vivencia o } \\
\text { processo de adoecimento e } \\
\text { transplante renal. }\end{array}$ & $\begin{array}{l}\text { Qualitativa/Entrevista } \\
\text { semiestruturada e } \\
\text { análise de conteúdo }\end{array}$ \\
\hline $\begin{array}{l}\text { La Longuiniere, } \\
\text { Yarid, Silva (2018) } \\
\text { SCIELO }\end{array}$ & $\begin{array}{l}\text { Influência da } \\
\text { religiosidade/espiritualid } \\
\text { ade do profissional de } \\
\text { saúde no cuidado do } \\
\text { paciente crítico }\end{array}$ & $\begin{array}{l}\text { Verificar se a religiosidade } \\
\text { influencia no processo de } \\
\text { cuidar de pacientes críticos. }\end{array}$ & $\begin{array}{l}\text { Caráter transversal } \\
\text { com abordagem } \\
\text { quantitativa/Questioná } \\
\text { rios e análise descritiva } \\
\text { e de associação }\end{array}$ \\
\hline $\begin{array}{l}\text { Paula, Nascimento, } \\
\text { Rocha (2009) } \\
\text { SCIELO }\end{array}$ & $\begin{array}{l}\text { Religião e espiritualidade: } \\
\text { experiência de famílias } \\
\text { de crianças com } \\
\text { Insuficiência Renal } \\
\text { Crônica. }\end{array}$ & $\begin{array}{l}\text { Descrever as manifestações de } \\
\text { religiosidade e espiritualidade } \\
\text { de famílias de crianças em } \\
\text { diálise peritoneal. }\end{array}$ & $\begin{array}{l}\text { Qualitativo/Estudo de } \\
\text { múltiplos casos e } \\
\text { análise de conteúdo. }\end{array}$ \\
\hline $\begin{array}{l}\text { Dinis, Ferreira, } \\
\text { Carvalho (2014) } \\
\text { SCIELO }\end{array}$ & $\begin{array}{l}\text { Familiar cuidador da } \\
\text { pessoa com psicose: } \\
\text { satisfação na prestação } \\
\text { de cuidados. }\end{array}$ & $\begin{array}{l}\text { Descrever a satisfação do } \\
\text { familiar cuidador e suas as } \\
\text { fontes de satisfação. }\end{array}$ & $\begin{array}{l}\text { Quantitativo/ } \\
\text { Questionários e análise } \\
\text { descritiva e de } \\
\text { associação }\end{array}$ \\
\hline $\begin{array}{l}\text { Siqueira, Cecagno, } \\
\text { Medeiros, Sampaio, } \\
\text { Rangel (2017) } \\
\text { BDENF }\end{array}$ & $\begin{array}{l}\text { Espiritualidade no } \\
\text { processo saúde-doença- } \\
\text { cuidado do usuário } \\
\text { oncológico: olhar do } \\
\text { enfermeiro. }\end{array}$ & $\begin{array}{l}\text { Analisar a espiritualidade no } \\
\text { processo saúde-doença- } \\
\text { cuidado do usuário oncológico, } \\
\text { sob o olhar do enfermeiro. }\end{array}$ & $\begin{array}{l}\text { Qualitativa/Entrevista } \\
\text { semiestruturada e } \\
\text { análise de conteúdo }\end{array}$ \\
\hline $\begin{array}{l}\text { Silva, Aquino, Silva } \\
\text { (2016) } \\
\text { CINAHL }\end{array}$ & $\begin{array}{l}\text { As relações entre } \\
\text { espiritualidade e cuidado } \\
\text { segundo as concepções } \\
\text { de estudantes de } \\
\text { enfermagem. }\end{array}$ & $\begin{array}{l}\text { Investigar as concepções de } \\
\text { estudantes de enfermagem } \\
\text { acerca da espiritualidade no } \\
\text { contexto saúde/doença. }\end{array}$ & $\begin{array}{l}\text { Qualitativa/Questionári } \\
\text { o e entrevista e análise } \\
\text { de conteúdo }\end{array}$ \\
\hline $\begin{array}{l}\text { Correia, Cavalcanti, } \\
\text { Freitas, Oliveira, } \\
\text { Tochetto (2016) } \\
\text { CINAHL }\end{array}$ & $\begin{array}{l}\text { A importância da } \\
\text { religiosidade/espiritualid } \\
\text { ade na perspectiva dos } \\
\text { pacientes oncológicos. }\end{array}$ & $\begin{array}{l}\text { Descrever a importância da } \\
\text { religiosidade/espiritualidade no } \\
\text { processo saúde-doença sob a } \\
\text { percepção de pacientes } \\
\text { oncológicos }\end{array}$ & $\begin{array}{l}\text { Quantitativo/Questioná } \\
\text { rio e análise descritiva }\end{array}$ \\
\hline
\end{tabular}

Fonte: Os autores (2020).

Os principais achados dos estudos são descritos a seguir, tendo os mesmos sido organizados em categorias temáticas, sendo elas: A influência da religiosidade em situações específicas de adoecimento; Os profissionais de saúde e a espiritualidade; Saberes e práticas espirituais e a sua relação com o processo saúde-doença.

\section{A influência da religiosidade em situações específicas de adoecimento}

Nessa categoria discutem-se os achados dos estudos que buscaram compreender a influência que a espiritualidade e ou religiosidade tem nas vivências de adoecimento. As principais doenças descritas na literatura foram o câncer e os problemas renais.

As práticas e crenças religiosas mostraram-se como instrumentos de enfrentamento e como redes de apoio social para as pessoas que passaram por terapia de substituição renal (hemodiálise ou diálise peritoneal) e por cirurgia de transplante renal, assim como para os seus familiares. A fé foi apontada como o subsídio necessário para compreensão e aceitação do processo de adoecimento e as instituições religiosas e os seus adeptos colocaram-se como mecanismos de apoio e auxílio nesse processo ${ }^{12-14}$. 
Estudos desenvolvidos com pessoas em tratamento para o câncer também evidenciaram a espiritualidade como um importante meio para encontrar apoio social e enfrentamento pessoal, além disso, identificou-se que a fé nessas situações pode ser uma importante forma de garantir força pró-social e funcionar como método de controle comportamental. Os artigos mostraram ainda que as pessoas nessa condição mais religiosas são as mulheres e as pessoas mais idosas, além de que existe uma correlação entre espiritualidade e melhor qualidade de vida ${ }^{15-16}$.

Em pesquisa desenvolvida na atenção básica, mais especificamente em grupos de Terapia Comunitária Integrativa, verificou-se que os principais problemas vivenciados pelos participantes estavam associados ao estresse relacionado às situações de rotina da família e do trabalho, como principal fonte de enfrentamento dessas adversidades, os respondentes da pesquisa indicaram a fé e a espiritualidade ${ }^{17}$.

No contexto do familiar cuidador de pessoas com transtornos mentais a espiritualidade foi apontada como um fator que garante satisfação nesse processo de cuidar, já que, configura uma visão de mundo na qual o seu papel como cuidador ganha um significado especial, com aspectos positivos e de esperança ${ }^{18}$.

Com relação a doenças estigmatizantes, essa relação pode se configurar de maneira diferente, como mostra a pesquisa desenvolvida com pessoas que vivem com o vírus da Imunodeficiência Humana Adquirida (HIV), na qual os entrevistados evidenciaram que instituições religiosas não se mostraram acolhedoras quando souberam das suas condições, muito embora todos tenham afirmado que a espiritualidade e a fé são essenciais para o enfrentamento da doença e para garantir a continuidade do tratamento ${ }^{19}$.

\section{Os profissionais de saúde e a espiritualidade}

Nessa categoria temática, concentram-se os estudos que se debruçaram sobre os aspectos que envolvem a visão dos profissionais de saúde acerca da efetivação de um cuidado em saúde que considere questões espirituais e religiosas. Verificaram-se pesquisas desenvolvidas nos níveis de atenção primária e terciária, assim como, artigos que se preocuparam em abordar questões concernentes ao processo de formação dos trabalhadores da saúde.
Em estudo desenvolvido com médicos de família e comunidade, buscou-se conhecer a percepção que os mesmos têm acerca da espiritualidade no cuidado dos usuários desses serviços, verificou-se que esses profissionais não haviam tido um processo de formação que se preocupasse com essas questões, tendo que, dessa forma, aprender a abordar essa temática com a experiência clínica. Concluiu-se que a abordagem desses aspectos pode estreitar a relação existente entre profissionais e usuários do serviço, tendo em vista que permite conhecer de forma mais intima os mesmos e aumenta o vínculo e a confiança nos serviços de saúde ${ }^{20}$.

De maneira semelhante, pesquisas desenvolvidas com enfermeiros que atuam em níveis de atenção mais especializados, no caso, em Unidades de Tratamento Intensivo e oncologia, também indicam a espiritualidade como um aspecto que contribui para o processo saúde-doença, modificando a forma de prestar a assistência a saúde ${ }^{21}$. Os profissionais percebem a espiritualidade como uma forma de enfrentamento e afirmam identificar diferenças no que diz respeito aos pacientes que possuem alguma religião daqueles que não têm. Os profissionais acreditam que a espiritualidade permite um maior controle emocional e psicológico $\stackrel{22}{ }$.

Pensando especificamente no processo formativo dos profissionais, dois estudos buscaram compreender a percepção de acadêmicos de enfermagem e medicina acerca da relação entre espiritualidade e o processo saúde doença. Os estudantes apontaram a espiritualidade como um recurso terapêutico muito importante, principalmente nas situações de terminalidade da vida, além de o indicarem como fator necessário para garantir a humanização da assistência e um cuidado holístico, que leve em consideração todos os aspectos do indivíduo ${ }^{23-24}$.

\section{Saberes e práticas espirituais e a sua relação com o processo saúde-doença}

Essa categoria temática congrega os estudos que se preocuparam de maneira mais específica com as práticas espirituais desenvolvidas na perspectiva do cuidado em saúde, as pesquisas foram realizadas de maneira mais intima com as instituições espirituais, em contato com atores importantes para tais comunidades, além de buscaram compreender de forma pormenirizada como as práticas de cura espiritual se processam. 
Estudo desenvolvido na atenção básica de cidades interioranas do estado de Minas Gerais investigou as práticas de saúde desenvolvidas por seus usuários. Os usuários relataram fazer uso de banhos, chás e rezas (práticas de benzimento) para chagarem a cura. A fé foi identificada como um recurso terapêutico em duas modalidades, uma em que é tido como essencial e outra utilizada como recurso adjuvante de tratamentos convencionais. No âmbito do entendimento acerca da saúde por parte dos entrevistados, verificou-se que os mesmos associam o estar saudáveis a condição de conseguir realizar atividades da vida cotidiana, assim como, aspectos relacionados higiene e aspectos do funcionamento do corpo. $O$ estudo evidenciou que os entrevistados tendem a procurar ajuda médica quando as alternativas espirituais e tradicionais não surtiram efeitos positivos ${ }^{25}$.

Os demais estudos tiveram suas perspectivas de investigação direcionadas aos adeptos de religiões de matrizes africanas. Percebeu-se que as doenças para a umbanda podem ter um significado espiritual, ligadas aos orixás de cada indivíduo, embora seja reconhecida a necessidade de complementaridade com práticas de cura biomédicas. As ações de cura são oferendas a entidades espirituais, orações, banhos e limpezas de descarrego. A espiritualidade está muito mais guiada pela modificação do estilo de vida do que necessariamente na cura das enfermidades, trata-se de trazer significado a existência dos indivíduos. Salienta-se que as percepções sobre as doenças e a sua cura dependem da visão de mundo que os dirigentes dos terreiros possuem, não sendo uniformes ${ }^{26}$.

Por sua vez, outro estudo buscou compreender como se processavam os itinerários terapêuticos de pessoas que frequentavam centros de candomblé e discutir a relação estabelecida entre esses indivíduos e os serviços de saúde. Verificou-se que a busca pelo candomblé acontece na medida em que a ajuda médica não consegue curar determinadas doenças. As dificuldades concernentes ao estabelecimento de diálogos entre médicos e usuários são levantadas. Onde os profissionais não se apropriam de aspectos relacionados à espiritualidade, colocando em risco o estabelecimento de diagnósticos e condutas terapêuticas eficientes ${ }^{27}$.

\section{Discussão}

De maneira semelhante aos trabalhos científicos e acadêmicos encontrados na busca dessa revisão de literatura, outros autores indicam a fé e a espiritualidade como fatores adjuvantes no processo de cuidado e enfrentamento do adoecimento. Observou-se, tal qual aos estudos citados nos resultados, que a fé e a espiritualidade são importantes, principalmente nas situações em que o adoecimento é crônico, a exemplo dos tratamentos de câncer e de patologias renais ${ }^{28-30}$.

Em estudo desenvolvido com mulheres que passaram pelo tratamento de câncer de mama, verificou-se que as mesmas visualizavam a espiritualidade e a fé religiosa como instrumentos para superar as adversidades do tratamento, assim como, garantir a esperança na cura através das intervenções terapêuticas ${ }^{28}$. Os pacientes em tratamento para essa doença buscam a espiritualidade enquanto método para minimizar seu sofrimento, sendo essencial que os profissionais da saúde reconheçam essa necessidade e assim possam ofertar uma assistência mais humanizada ${ }^{29}$.

Estratégias como a utilização de preces e orações destinadas às pessoas em terapia de hemodiálise mostraram-se eficazes no tocante ao alívio do sofrimento vivenciado pelos pacientes nessa situação ${ }^{30}$. Em ensaio clínico controlado, randomizado e duplo cego, percebeu-se que após sessões de preces e orações, os pacientes em tratamento para insuficiência renal crônica apresentavam melhora nos valores da pressão arterial, frequência cardíaca e respiratória ${ }^{30}$.

No tocante a relação existente entre os profissionais da saúde e a religiosidade e espiritualidade, outros autores corroboram com os achados do presente estudo ao afirmarem que ao preocuparem-se com essas temáticas em seu cotidiano, os trabalhadores da saúde avançam no sentido de uma atenção à saúde que rompe os limites do saber biomédico, alcançando paradigmas na saúde de maneira que visualizam seus pacientes inseridos em um contexto sistêmico ${ }^{31}$. 
Em contrapartida, percebe-se ainda uma discussão escassa dessa temática no processo de formação dos profissionais de saúde, o que pode implicar de maneira negativa na forma como os trabalhadores se sentem frente ao entendimento das formas que a espiritualidade e religiosidade podem impactar no enfrentamento das doenças ${ }^{32}$. Autores apontam a necessidade de maior inserção dessas temáticas nas grades curriculares das graduações em saúde, além da criação de cursos de formação continuada para os profissionais já inseridos nos serviços de saúde, o que poderia garantir mais segurança aos mesmos quando deparados com tais problemáticas em seu cotidiano $^{33}$. Tais achados também se aproximam das discussões feitas por autores identificados na literatura a partir da presente revisão.

Com relação aos saberes e práticas espirituais mais especificamente, em consonância com os achados da busca de dados do presente estudo, percebe-se que outros autores apontam que os sujeitos podem fazer uso de banhos, chás, simpatias e benzimentos para o cuidado de pessoas vivenciado experiências de adoecimento. Nesse cenário figuram sujeitos(as) conhecidos(as) como benzedeiros (as), que muitas vezes utilizam plantas medicinais para viabilizar tais práticas de cuidado. A lógica que impera nessas relações é a de trocar, receber e retribuir, não a de vender ou cobrar ${ }^{35}$.

Por lançarem mão de insumos naturais para viabilizar seus saberes e práticas espirituais, esses indivíduos estabelecem outra relação com o ambiente em que vivem, onde o ecossistema que os cerca é visualizado como parte integrante da sua saúde, visualizando a sua condição para além do adoecimento $\frac{35}{\text {. Importante }}$ salientar que os saberes e práticas espirituais podem desenvolver-se de maneiras distintas a depender da realidade cultural em questão, das formas de aquisição desses conhecimentos e das experiências pregressas que os sujeitos envolvidos detêm ${ }^{36}$.

De maneira geral tais práticas de cuidado estão ligadas a cultura popular de uma determinada região, possuindo um discurso que muitas vezes oferece um contraponto ao modelo biomédico de entender saúde, que se centra na doença e não nos indivíduos ${ }^{37}$.

\section{Considerações finais}

A partir das evidências encontradas na literatura, observou-se que a religiosidade e a espiritualidade são encaradas como importantes mecanismos de apoio social e de enfrentamento pessoal as situações de adoecimento, principalmente aquelas relacionadas a doenças de curso crônico. Os profissionais da saúde por mais que apontem esse aspecto da vida humana como essencial no processo de cuidar, afirmam que seus processos de formação não abordaram de maneira adequada tais aspectos, havendo uma lacuna entre o saber e o fazer.

Verificou-se que as práticas espirituais de cura são as rezas, benzimentos, banhos e limpezas espirituais. Percebe-se uma menor quantidade de estudos preocupados em estudar as práticas e os saberes de cura no local onde essas ações se processam, sendo a percepção de pessoas que passaram por processos de adoecimento e profissionais de saúde o principal interesse da maioria dos estudos dessa pesquisa. Nesse sentido, aponta-se a necessidade de compreender melhor as motivações envolvidas na procura de medicinas tradicionais relacionadas a espiritualidade, os tipos de doenças envolvidas nessa busca e as práticas de cura pela fé desenvolvidas.

\section{Contribuições dos autores}

Lima Filho FJR participou da concepção, delineamento, busca e análise dos dados da pesquisa, interpretação dos resultados e redação. Lima NKG participou da coleta de dados, interpretação dos dados e revisão do artigo. Vieira NR participou da interpretação dos dados e revisão do artigo.

\section{Conflitos de interesses}

Nenhum conflito financeiro, legal ou político envolvendo terceiros (governo, empresas e fundações privadas, etc.) foi declarado para nenhum aspecto do trabalho submetido (incluindo, mas não se limitando a subvenções e financiamentos, participação em conselho consultivo, desenho de estudo, preparação de manuscrito, análise estatística, etc.). 


\section{Referências}

1. Panzine RG, Rocha NS, Bandeira DR, Fleck MPA. Qualidade de vida e espiritualidade. Rev Psiq Clín. 2007;34 (supl 1):105-115. doi: 10.1590/S0101-60832007000700014

2. Koenig HG, Larson DB, Larson SS. Religion and Coping with Serious Medical Illness. Ann Pharmacother 2001;35(3):352-359. doi: 10.1345/aph.10215

3. Almeida AM, Lucchetti G. Panorama das pesquisas em ciência, saúde e espiritualidade. Cienc Cult. 2016;68(1):54-57. doi: $\underline{10.21800 / 2317-66602016000100016}$

4. Foch GFL, Silva AMB, Enumo SRF. Coping religioso/espiritual: uma revisão sistemática de literatura (2003-2013). Arq Bras Psicol. 2017;69(2):53-71.

5. Inoue TM, Vecina MVA. Espiritualidade e/ou religiosidade e saúde: uma revisão de literatura. J Health Sci Inst. 2017;35(2):127130.

6. Broncas IMO. Espiritualidade e estado de saúde na doença crónica: papel mediador do coping e da adesão ao tratamento [dissertação]. Lisboa: Instituto Universitário Ciências Psicológicas, sociais e da vida; 2016.

7. Matos JRB. A influência da espiritualidade nas doenças oncológicas [dissertação]. Lisboa: Faculdade de medicina da Universidade de Coimbra; 2016.

8. Castilho CN, Cardoso PT. Espiritualidade, religiosidade e religião nas políticas públicas de saúde: um olhar para a integralidade. REFACS. 2015;3(1):28-39. doi: 10.18554/refacs.v3i1.1032

9. Arrieira ICO, Thofehrn MB, Porto AR, Palma JS. Espiritualidade na equipe interdisciplinar que atua em cuidados paliativos às pessoas com câncer. Cienc Cuid Saude 2011;10(2):314-321. doi: 10.4025/cienccuidsaude.v10i2.15689

10. World Health Organization (WHO). WHO traditional medicine strategy: 2014-2023 [Internet]. 2013. Disponível em: https://www. who.int/medicines/publications/traditional/trm_strategy14_23/en/

11. Ursi ES, Galvão CM. Prevenção de lesões de pele no perioperatório: revisão integrativa da literatura. Rev Latino-am Enfermagem 2006;14(1):124-31.

12. Paula ES, Nascimento LC, Rocha SMM. Religião e espiritualidade: experiência de famílias de crianças com Insuficiência Renal Crônica. Rev Bras Enferm. 2009;62(1):100-6. doi: $\underline{10.1590 / S 0034-71672009000100015}$

13. Borges DCS, Furino FO, Barbieri MC, Souza ROD, Alvarenga WA, Dupas G. A rede e apoio social do transplantado renal. Rev Gaúcha Enferm. 2016;37(4):1-7. doi: 10.1590/19831447.2016.04.59519
14. Cruz MGS, Daspett C, Roza BA, Ohara CVS, Hosta ALM. Vivência da família no processo de transplante de rim de doador vivo. Acta Paul Enferm. 2015;28(3):275-80. doi: 10.1590/1982$\underline{0194201500046}$

15. Correia DS, Cavalcanti SL, Freitas DA, Oliveira BC, Tochetto TMDB. A importância da religiosidade/espiritualidade na perspectiva dos pacientes oncológicos. Rev Enferm. 2016;10(8):2895-905.

16. Pinto C, Ribeiro JL. Avaliação da espiritualidade dos sobreviventes de cancro: implicações na qualidade de vida. Rev Port Sau Púb. 2010;28(1):49-56.

17. Rocha IA, Sá ANP, Braga LAV, Ferreira Filha MO, Dias MD. Terapia comunitária integrativa: situações de sofrimento emocional e estratégias de enfrentamento apresentadas por usuários. Rev Gaúcha Enferm. 2013;34(2):155-162. doi: 10.1590/ S1983-14472013000300020

18. Dinis C, Ferreira TR, Carvalho JC. Familiar cuidador da pessoa com psicose: satisfação na prestação de cuidados. Revista Portuguesa de Enfermagem de Saúde Mental. 2014;(Ed.Esp.1):5964.

19. Ferreira DC, Favoreto CAO, Guimarães MBL. The influence of religiousness on living with HIV. Interface. 2012;16(41):383-93. doi: $\underline{10.1590 / \text { S1414-32832012005000019 }}$

20. Fernandes MG. A Medicina centrada na pessoa: o componente espiritual na abordagem pelo médico de família e comunidade [dissertação]. Rio de Janeiro: Escola Nacional de Saúde Pública Sérgio Arouca; 2015.

21. La Longuiniere ACF, Yarid SD, Silva ECS. Influência da religiosidade/espiritualidade do profissional de saúde no cuidado do paciente crítico. Rev Cuid. 2018;9(1):1961-72. doi: 10.15649/ cuidarte.v9i1.413

22. Siqueira $\mathrm{HCH}$, Cecagno D, Medeiros AC, Sampaio AD, Rangel RF. Espiritualidade no processo saúde-doença-cuidado do usuário oncológico: olhar do enfermeiro. Rev enferm UFPE on line. 2017;11(8):2996-3004. doi: 10.5205/reuol.11064-98681-4ED.1108201702

23. Silva JB, Aquino TAA, Silva AF. As relações entre espiritualidade e cuidado segundo as concepções de estudantes de enfermagem. Rev enferm UFPE online. 2016;10(3):1029-37. doi: 10.5205/ reuol.8702-76273-4-SM.1003201612

24. Reginato V, Benedetto MAC, Gallian DMC. Espiritualidade e saúde: uma experiência na graduação em medicina e enfermagem. Trab Educ Saúde. 2016;14(1): 237-255. doi: 10.1590/1981-7746-sip00100

25. Soares AN, Morgan BS, Santos FBO, Matozinhos FP, Penna CMM. Crenças e práticas de saúde no cotidiano de usuários da rede básica de saúde. Rev Enferm UERJ. 2014;22(1):83-8. 
26. Mello MLBC. Práticas terapêuticas populares e religiosidade afro-brasileira em terreiros no Rio de Janeiro: um diálogo possível entre saúde e antropologia [tese]. Rio de Janeiro: Escola Nacional de Saúde Pública Sérgio Arouca; 2013.

27. Portugal CM. Entre o consultório e o terreiro: mediações, ruídos silenciamentos nos itinerários terapêuticos de adeptos do candomblé. RECIIS - Rev Eletron Comun Inf Inov Saúde. 2016;10(1):1-14. doi: 10.29397/reciis.v10i1.955

28. Kunz JA, Conde CR, Lemos TMR, Barros AES, Ferreira MLSM. A Religiosidade e Espiritualidade de Mulheres com Câncer de Mama Submetidas a Tratamento Cirúrgico. Revista Enfermagem Atual. 2018;86(24): 1-14. doi: 10.31011/reaid-2018-v.86-n.24-art.80

29. Guerrero GP, Zago MMF, Sawada NO, Pinto MH. Relação entre espiritualidade e câncer: perspectiva do paciente. Rev Bras Enferm. 2011;64(1):53-9. doi: 10.1590/S0034-71672011000100008

30. Brasileiro TOZ, Prado AAO, Assis BB, Nogueira DA, Lima RS, Chaves ECL. Effects of prayer on the vital signs of patients with chronic kidney disease: randomized controlled trial. Rev Esc Enferm. 2017;51:e03236. doi: 10.1590/S1980-220X2016024603236

31. Pinheiro LAA, Vilagra SMBW, Pinheiro CFA, Almeida Junior EHR, Souza MCA. A espiritualidade no cuidado em saúde na Atenção Primária. Revista PróUniverSUS. 2019;10(2):70-74. doi: $10.21727 /$ rpu.v10i2.2053
32. Silva BS, Costa EE, Gabriel IGSPS, Silva AE, Machado RM. Percepção de equipe de enfermagem sobre espiritualidade nos cuidados de final de vida. Cogitare Enferm. 2016;21(4):01-08. doi: $\underline{10.5380 / c e . v 21 i 4.47146}$

33. Silva TD, Marques LF. Percepções dos profissionais de saúde do SUS sobre religiosidade/espiritualidade no contexto hospitalar. Saberes Plurais: Educação na Saúde. 2018;2(2):134-47.

34. Lima CAB, Lima ARA, Mendonça CV, Lopes CV, Heck RM. O uso das plantas medicinais e o papel da fé no cuidado familiar. Rev Gaúcha Enferm. 2016;37(esp):e68285. doi: 10.1590/19831447.2016.esp.68285

35. Zank S, Peroni N, Araújo EL, Hanazaki N. Local health practices and the knowledge of medicinal plants in a Brazilian semi-arid region: environmental benefits to human health. J Ethnobiology Ethnomedicine. 2015;11(11). doi: 10.1186/1746-4269-11-11

36. Cunha LA, Assunção LC. Abençoada cura: poéticas da voz e saberes de benzedeiras. Revista Brasileira de História das Religiões. 2016;9(27):189-227. doi: 10.4025/rbhranpuh. v9i27.31436

37. Silva VAG. As benzedeiras tradicionais de Curitiba: Identificação e análises. Revista Relegens Thréskeia. 2012;1(1):144-57. doi: 10.5380/rt.v1i1.31048 